\title{
Attenuation of Immune-Mediated Renal Injury by Telmisartan, an Angiotensin Receptor Blocker and a Selective PPAR- $\gamma$ Activator
}

\author{
Yuki Hamano ${ }^{\text {a }}$ Takashi Okude $^{\mathrm{b}}$ Osamu Yokosuka ${ }^{\mathrm{c}}$ \\ Makoto Ogawa ${ }^{a, c}$ \\ ${ }^{a}$ Department of Nephrology, Chiba University Hospital, and ${ }^{b}$ Department of Drug \\ Information and Communication, Graduate School of Pharmaceutical Sciences, and \\ 'Department of Medicine and Clinical Oncology, Graduate School of Medicine, Chiba \\ University, Chiba, Japan
}

\section{Key Words}

Angiotensin II receptor blocker $\cdot$ Glomerular basement membrane $\cdot$ Nephritis $\cdot$ Peroxisome proliferator-activated receptor- $\gamma$

\begin{abstract}
Background/Aims: Anti-glomerular basement membrane (GBM) nephritis is characterized by activation of the renin-angiotensin system. This study aimed to determine the question of whether a temporary angiotensin II blockade at the initial stage of anti-GBM nephritis is able to attenuate the disease as well as differences in renoprotection among angiotensin II receptor blockers (ARBs) with distinct peroxisome proliferator-activated receptor (PPAR)- $\gamma$-modulating activities. Methods: C57BL/6J mice were immunized with rabbit IgG, followed by intravenous injection of rabbit antimouse antibodies. Mice were then treated with telmisartan, losartan, and telmisartan + GW9662 (a PPAR- $\gamma$ antagonist) for 5 days, or hydralazine for 9 days. On days 8 and 13, mice were sacrificed to obtain tissues for histological analysis. Results: The temporary administration of telmisartan significantly suppressed glomerular damage compared to hydralazine. Losartan showed a similar effect but was less effective. Co-administration of GW9662 attenuated the renoprotective effect of telmisartan, almost to levels observed with losartan. In particular, it limited the decreased infiltration of inflammatory cells and preservation of capillaries in the glomeruli induced by telmisartan. Conclusion: Temporary angiotensin II blockade at the initial stage of anti-GBM disease dramatically inhibited its progression. In addition to a class effect of ARBs, telmisartan modified inflammation and endothelial damage in the kidney through its PPAR- $\gamma$-agonistic action.
\end{abstract}

Copyright $\odot 2011$ S. Karger AG, Basel

Dr. Yuki Hamano

1-8-1 Inohana, Chuo-ku

Chiba-shi, Chiba 260-8677 (Japan)

Tel. +81432262083

E-Mail hamano@faculty.chiba-u.jp 


\section{Introduction}

Anti-glomerular basement membrane (GBM) nephritis has been most widely studied experimentally as a representative of immune-mediated renal diseases. Anti-GBM disease is characterized by damage to the GBM followed by the invasion of inflammatory cells such as neutrophils, macrophages and CD8+ T cells and the destruction of the glomerular capillary network, culminating in glomerular sclerosis $[1,2]$. Monocyte chemoattractant protein-1 (MCP-1) has been demonstrated to be a dominant chemokine involved in macrophages/ monocytes in anti-GBM nephritis [3, 4].

The activation of the renin-angiotensin system (RAS) and increases in glomerular MCP1 levels were detected at an early stage of anti-GBM nephritis [5]. The glomerular damage and MCP-1 expression were dramatically reduced in the kidneys of angiotensin II type 1 receptor $\left(\mathrm{AT}_{1} \mathrm{R}\right)$-deficient mice. This suggested that RAS activation plays a critical role in inflammation during anti-GBM disease [5]. The clinical benefits of angiotensin receptor blockers (ARBs) have been well established in chronic kidney disease patients with diabetic and non-diabetic nephropathies [6, 7]. However, whether ARBs would be effective in suppressing acute onset of inflammatory disorders in the kidney remains to be determined.

In 1995, Lehmann et al. [8] discovered that peroxisome proliferator-activated receptor (PPAR)- $\gamma$ is the intracellular high-affinity receptor for the insulin-sensitizing and anti-diabetic thiazolidinediones, the activation of which blocked adipogenesis and differentiation into mature adipocytes. Ligand activation of PPAR- $\gamma$ also downregulated the transcription of genes encoding inflammatory cytokines, growth factors, proteolytic enzymes, adhesion molecules, chemokines and atherogenic factors $[9,10]$. Among many ARBs, telmisartan has been shown to constitute a unique subset of $\mathrm{AT}_{1}$ blockers capable of activating intracellular PPAR- $\gamma$. In contrast, losartan is another ARB but with little PPAR- $\gamma$ activity [11].

In this study, we demonstrated in a mouse model that the progression of anti-GBM disease was significantly inhibited by temporary administration of telmisartan or losartan at an early stage. Moreover, telmisartan provided additional therapeutic benefits by suppressing glomerular inflammation and endothelial injury through its PPAR- $\gamma$-mediated effects. With respect to renoprotection, losartan was less effective than telmisartan. Therefore, it is conceivable that the early administration of telmisartan could be an effective treatment option for patients with immune-mediated renal damage.

\section{Methods}

Mice and Reagents

Eight-week-old, female C57BL/6J mice were purchased from Japan SLC, Inc. (Shizuoka, Japan). All studies were reviewed and approved by the Animal Care and Use Committee of Chiba University. Telmisartan and losartan were kindly provided by Nippon Boehringer Ingelheim Co. and MSD K.K. (Tokyo, Japan), respectively. GW9662, a PPAR- $\gamma$ antagonist, was purchased from Sigma (St. Louis, Mo., USA).

\section{Induction of Accelerated Anti-GBM Glomerulonephritis}

Rabbit anti-GBM antiserum was prepared as previously described [12]. The C57BL/6J mice were immunized subcutaneously with $250 \mu \mathrm{g}$ of normal rabbit IgG in complete Freund's adjuvant. This was followed by intravenous injections of a total of $120 \mu \mathrm{l}$ of nephrotoxic serum 5 and 6 days later which, for purposes of experimental treatment, were considered as days 0 and 1 . Mice were treated with telmisartan $(15 \mathrm{mg} / \mathrm{kg} / \mathrm{day}$, i.p.), losartan $(20 \mathrm{mg} / \mathrm{kg} /$ day, i.p.), telmisartan + GW9662 (1, 3 or $10 \mathrm{mg} / \mathrm{kg} /$ day, i.p.) for 5 days (days $0-4$ ), or hydral- 
azine from Sigma ( $4 \mathrm{mg} / \mathrm{kg} /$ day, i.p.), to normalize blood pressure to the same levels that were seen in the telmisartan and losartan groups, for 9 days (days $0-8$ ) after the first injection of the anti-GBM antibodies. On days 4 and 8, blood pressure was measured using a sphygmomanometer (BP-98A; Softron, Tokyo, Japan). On days 8 and 13, serum and urine samples were collected to evaluate renal function, and mice were sacrificed to obtain tissues for histological study. Levels of blood urea nitrogen $(\mathrm{BUN})$, serum creatinine $\left(\mathrm{S}_{\mathrm{Cr}}\right)$ levels and urinary albumin excretion (UAE) were determined as previously described [12]. Three independent experiments were performed and representative data are shown in figures 1-7.

\section{Histological Analysis}

Morphologic changes in the glomeruli or tubulointerstitial areas were scored on a scale from 0 to 5: 0 , none of the glomeruli or no tubulointerstitial area was affected by morphologic changes; $1,<20 \% ; 2,<40 \% ; 3,<60 \% ; 4,<80 \%$, and $5,100 \%$ affected. In the analysis of glomeruli, scores were assigned separately for intraglomerular cell proliferation, glomerular thrombosis, and extracapillary cellular proliferation (crescent formation). The sum of the three scores was used in the analysis of glomeruli. For the interstitium, separate scores were assigned for infiltration of mononuclear cells, damage of tubules, and interstitial fibrosis, and the sum of the three scores was used for analysis. Semiquantitative analysis was performed as described previously [12]. The scoring was performed by two independent observers on blinded sections.

\section{Immunohistochemistry and Apoptosis Assay}

Immunohistochemical staining was performed as described previously [12]. For primary antibodies, rat anti-mouse CD31 (BD PharMingen, San Diego, Calif., USA), rat anti-mouse neutrophil (clone 7/4; Immunotech, Praha, Czech Republic), rat anti-mouse CD11b (BD PharMingen), or rat anti-mouse CD8a antibodies (BD PharMingen) were used. Apoptotic nuclei were detected as described previously [13].

\section{Real-Time Reverse Transcription-Polymerase Chain Reaction}

RT-PCR was performed as described previously [12]. The following gene-specific primers were used: MCP-1 - (forward) GCA TCC ACG TGT TGG CTC A and (reverse) CTC CAG CCT ACT CAT TGG GAT CA; vascular endothelial growth factor (VEGF) - (forward) CTG GAT ATG TTT GAC TGC TGT GGA and (reverse) GTT TCT GGA AGT GAG CCA ATG TG, and GAPDH (glyceraldehyde-3-phosphate dehydrogenase) - (forward) ATG GGG TGA GGC CGG TGC TG and (reverse) CTT GAT GTC ATC ATA CTT GG.

\section{Statistical Analysis}

The number of mice used for each experiment is indicated in the figure legends. Statistical analyses were performed using ANOVA. As needed, additional analysis was carried out using the $\mathrm{t}$ test with Bonferroni correction to identify significant differences. A value of $\mathrm{p}<$ 0.05 was considered to be statistically significant. The results are shown as means \pm SE.

\section{Results}

After induction of anti-GBM disease, administering telmisartan or losartan for 5 days resulted in a significant inhibition on day 8 of the hydralazine effect of elevating UAE and $\mathrm{S}_{\mathrm{Cr}}$ levels (fig. $1 \mathrm{a}-\mathrm{c}$ ). In addition, on day 13 the increase of BUN and $\mathrm{S}_{\mathrm{Cr}}$ levels seen in hydralazine-treated mice was suppressed only in the mice treated with telmisartan (fig. 1b, c). Nineday treatment with hydralazine had no effect on the progression of anti-GBM disease (fig. 1b, 

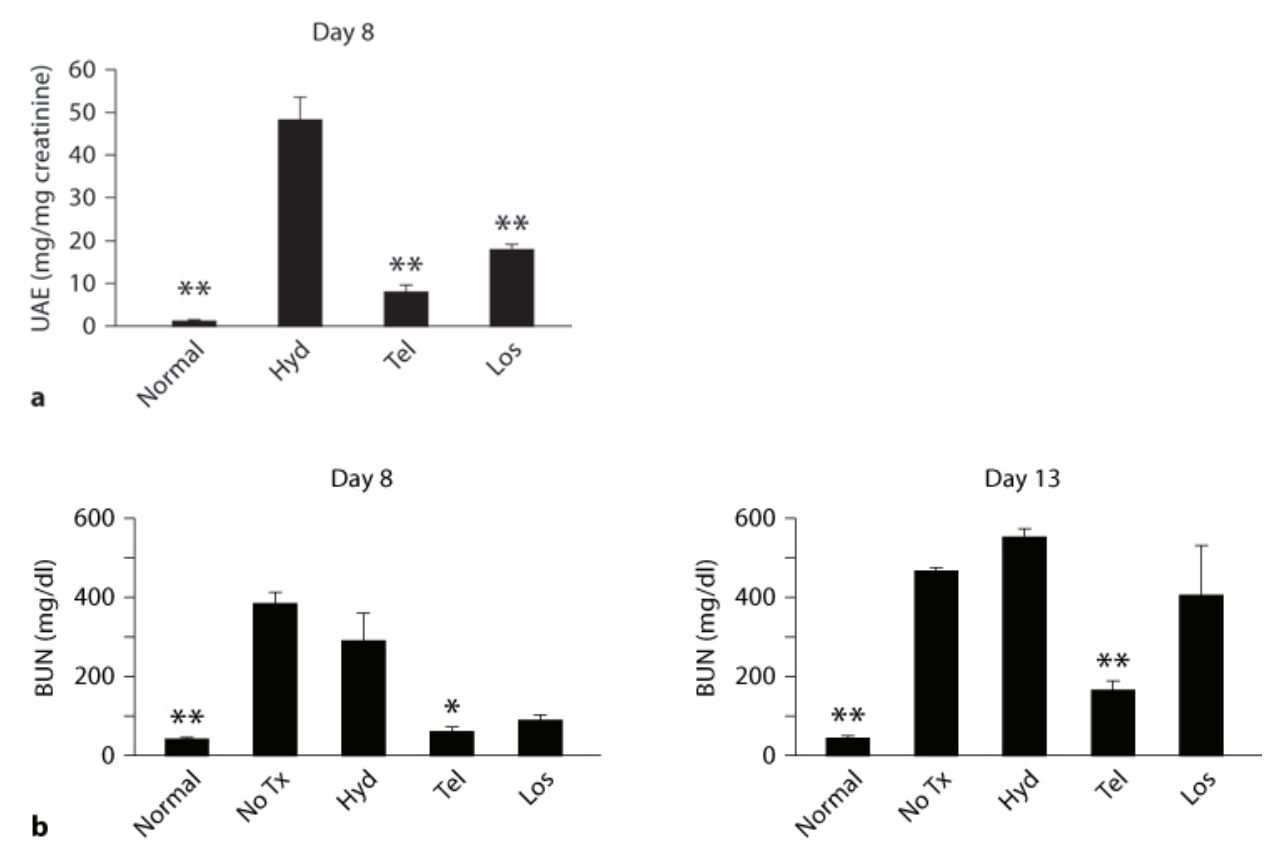

Day 8
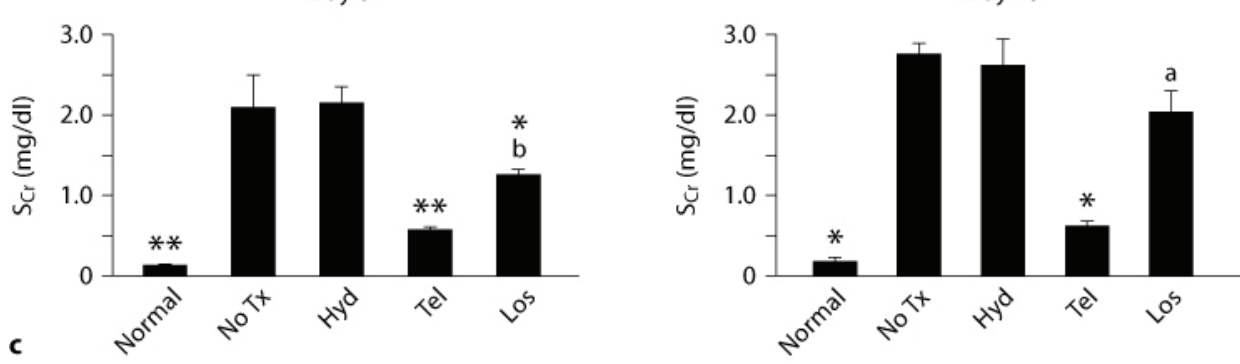

Day 8
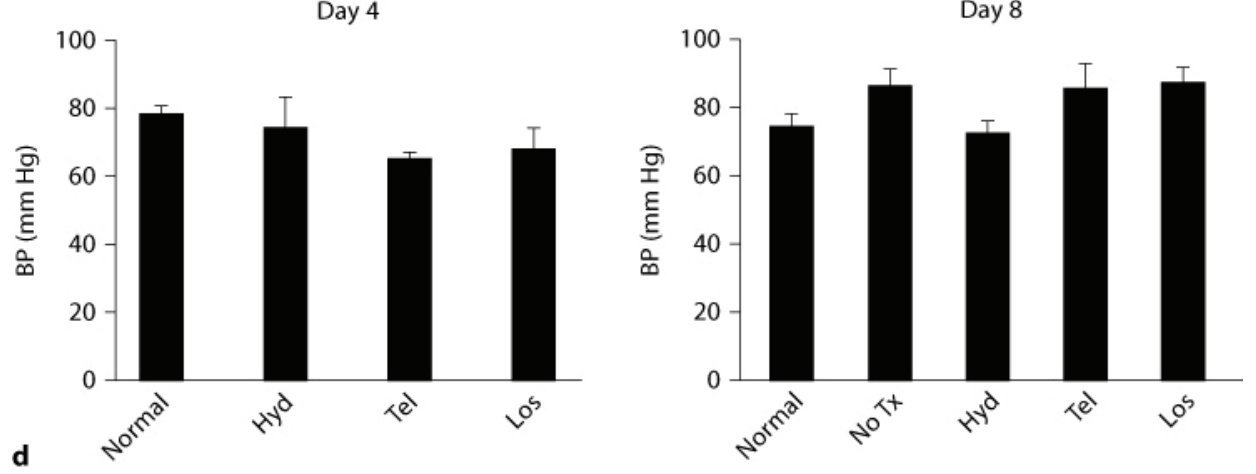

Fig. 1. $U A E(\mathbf{a}), B U N(\mathbf{b}), S_{C r}(\mathbf{c})$ and blood pressure $(B P ; \mathbf{d})$ were estimated in normal mice $(\mathrm{n}=5)$, nephritic mice without treatment (No Tx, $\mathrm{n}=10$ ) and those treated with hydralazine (Hyd, $\mathrm{n}=10$ ), telmisartan $($ Tel, $\mathrm{n}=10)$ or losartan (Los, $\mathrm{n}=10) .{ }^{*} \mathrm{p}<0.05,{ }^{* *} \mathrm{p}<0.01$, vs. hydralazine; ${ }^{\mathrm{a}} \mathrm{p}<0.05,{ }^{\mathrm{b}} \mathrm{p}<0.01$, vs. telmisartan. 


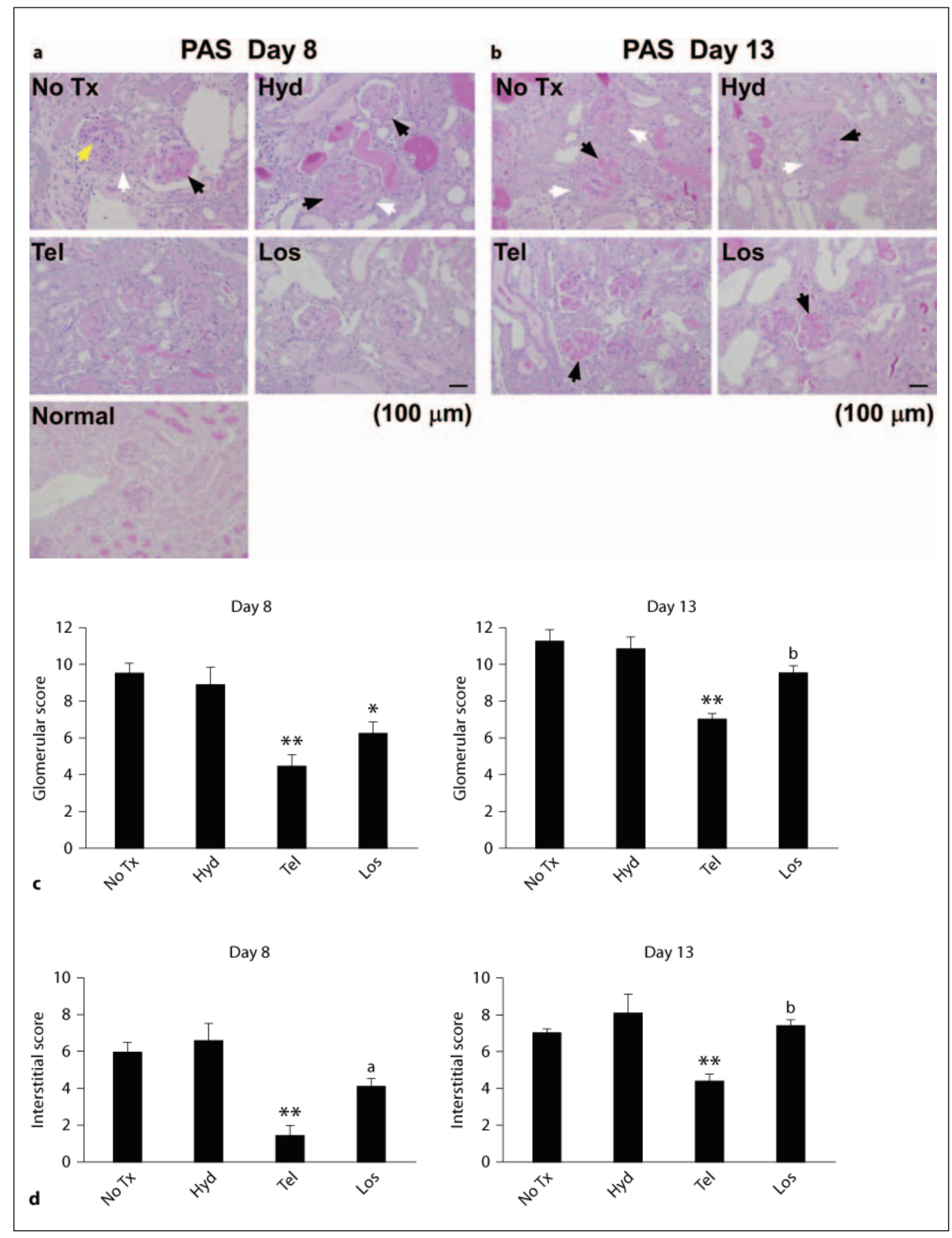

Fig. 2. Normal and nephritic kidneys (a, b) were stained with periodic acid-Schiff (PAS) reagents. Total glomerular (c) and tubulointerstitial (d) scores were estimated as described in the Methods section. The induction of anti-GBM nephritis in mice without treatment (No Tx) or hydralazine (Hyd)-treated mice contributed significantly to severe glomerular damage including glomerular proliferation (yellow arrowhead), thrombosis (black arrowheads) and crescent formation (white arrowheads), which was attenuated by telmisartan (Tel) or losartan (Los). ${ }^{*} \mathrm{p}<0.05,{ }^{*} \mathrm{p}<0.01$, vs. hydralazine, ${ }^{\mathrm{a}} \mathrm{p}<0.05,{ }^{\mathrm{b}} \mathrm{p}<0.01$, vs. telmisartan. 


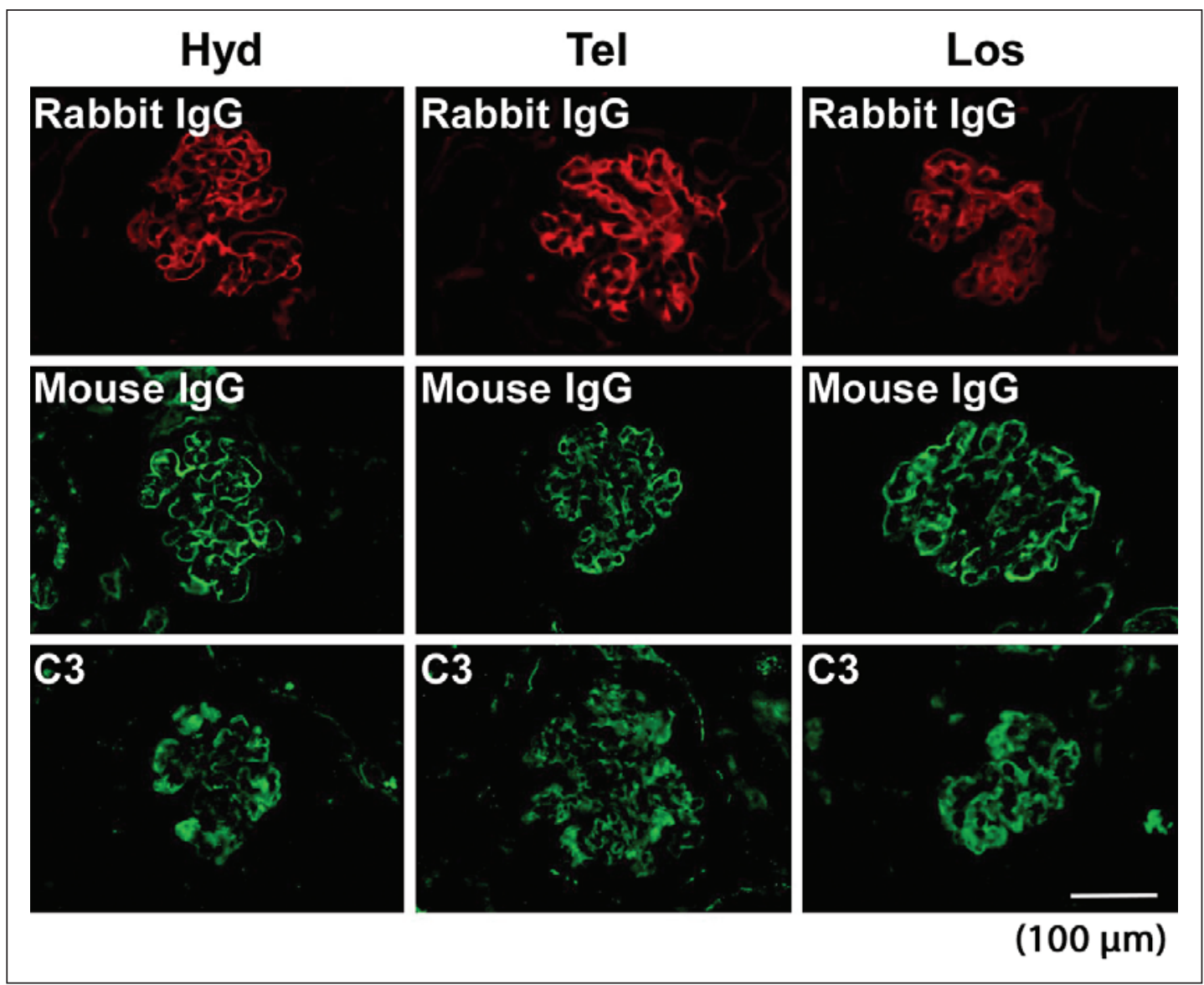

Fig. 3. Representative immunofluorescence staining for deposition of rabbit IgG, mouse IgG and C3 on glomeruli of hydralazine (Hyd)-, telmisartan (Tel)- or losartan (Los)-treated nephritic mice.

c, 2c, d). There was no difference in mean blood pressures among all groups on days 4 and 8 (fig. 1d).

Nephritic mice, whether treated or not treated with hydralazine, showed glomerular cell proliferation, thrombosis and crescent formation on days 8 and 13 (fig. 2a, b). Telmisartan or losartan administration significantly reduced the total glomerular score (composed of cell proliferation, thrombosis and crescent formation) on day 8 . The total score for the tubulointerstitium was decreased only in telmisartan-treated mice on day 8. Interestingly, for day 13 only telmisartan showed improvements in the glomerular and interstitial scores (fig. 2a-d). The administration of hydralazine, telmisartan or losartan did not affect deposition on the GBM of heterologous or autologous antibodies and complement on day 8 , as assessed by the binding of rabbit anti-GBM antibody, mouse IgG and C3, respectively (fig. 3).

To explore how telmisartan provides renoprotection during anti-GBM disease, the PPAR$\gamma$-modulating activity of telmisartan was examined [11]. Blocking of PPAR- $\gamma$ activity with GW9662 attenuated the telmisartan-mediated decrease in UAE, BUN and $\mathrm{S}_{\mathrm{Cr}}$ levels on day 8. In mice treated with a high dosage of GW9662, UAE and $\mathrm{S}_{\mathrm{Cr}}$ levels were similar to those in mice administered losartan with minimal PPAR- $\gamma$-modulating activity (fig. $1 \mathrm{a}-\mathrm{c}, 4 \mathrm{a}-\mathrm{c}$ ). The injection of a high dosage of GW9662 into normal mice had no effect on UAE and renal func- 
tion (fig. 4a-c; GW Only). The glomeruli from the mice injected a high dosage of GW9662 were enlarged with extensive thrombosis (black arrowheads) on day 8 (fig. 4d; GW High). Consistent with renal function, co-administration of a high dosage of GW9662 led to increased total scores for glomeruli and interstitium in a dose-dependent manner (fig. 4e, f; GW High). There was no difference in the amount of rabbit anti-GBM antibody, mouse IgG and C3 deposited along the GBM among GW9662-treated and other mouse groups (data not shown).

Glomerular infiltration of polymorphonuclear leukocytes, macrophages/monocytes and CD8+ T cells and MCP-1 expression were significantly increased over normal levels in hydralazine-treated mice on day 8 during anti-GBM disease. Telmisartan inhibited these effects of hydralazine (fig. 5). In the hydralazine-treated mice, the decrease in VEGF expression

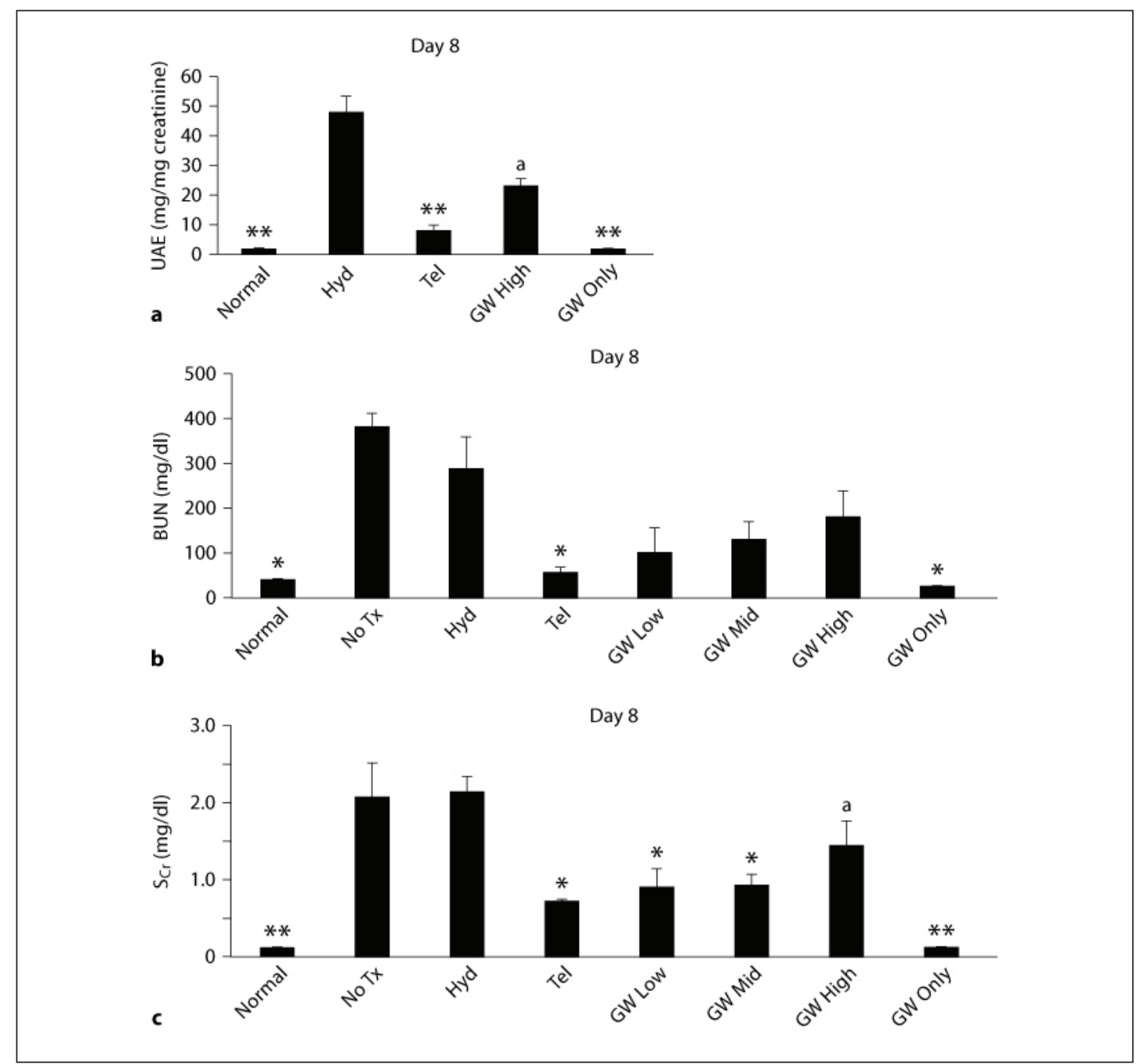

Fig. 4. $\mathrm{UAE}(\mathbf{a}), \mathrm{BUN}(\mathbf{b})$ and $\mathrm{S}_{\mathrm{Cr}}(\mathbf{c})$ were estimated in normal mice $(\mathrm{n}=5)$, normal mice injected $10 \mathrm{mg} /$ kg/day GW9662 (GW Only, $\mathrm{n}=5$ ), nephritic mice without treatment (No Tx, $\mathrm{n}=10$ ) and those treated with hydralazine (Hyd, $\mathrm{n}=10$ ), telmisartan (Tel, $\mathrm{n}=10$ ), telmisartan $+1 \mathrm{mg} / \mathrm{kg} / \mathrm{day}$ GW9662 (GW Low, $\mathrm{n}=5$ ), telmisartan $+3 \mathrm{mg} / \mathrm{kg} /$ day GW9662 (GW Mid, n = 5) or telmisartan $+10 \mathrm{mg} / \mathrm{kg} /$ day GW9662 (GW High, $\mathrm{n}=6$ ). Co-administration of GW9662 abrogated the improved renal function observed in telmisartan-treated mice in a dose-dependent manner. ${ }^{*} \mathrm{p}<0.05,{ }^{* *} \mathrm{p}<0.01$, vs. hydralazine, ${ }^{\mathrm{a}} \mathrm{p}<0.05$, vs. telmisartan. 


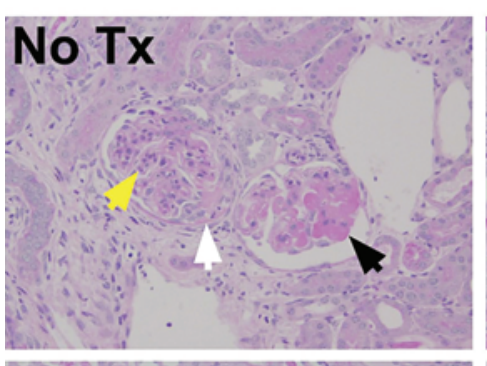

\section{PAS Day 8}
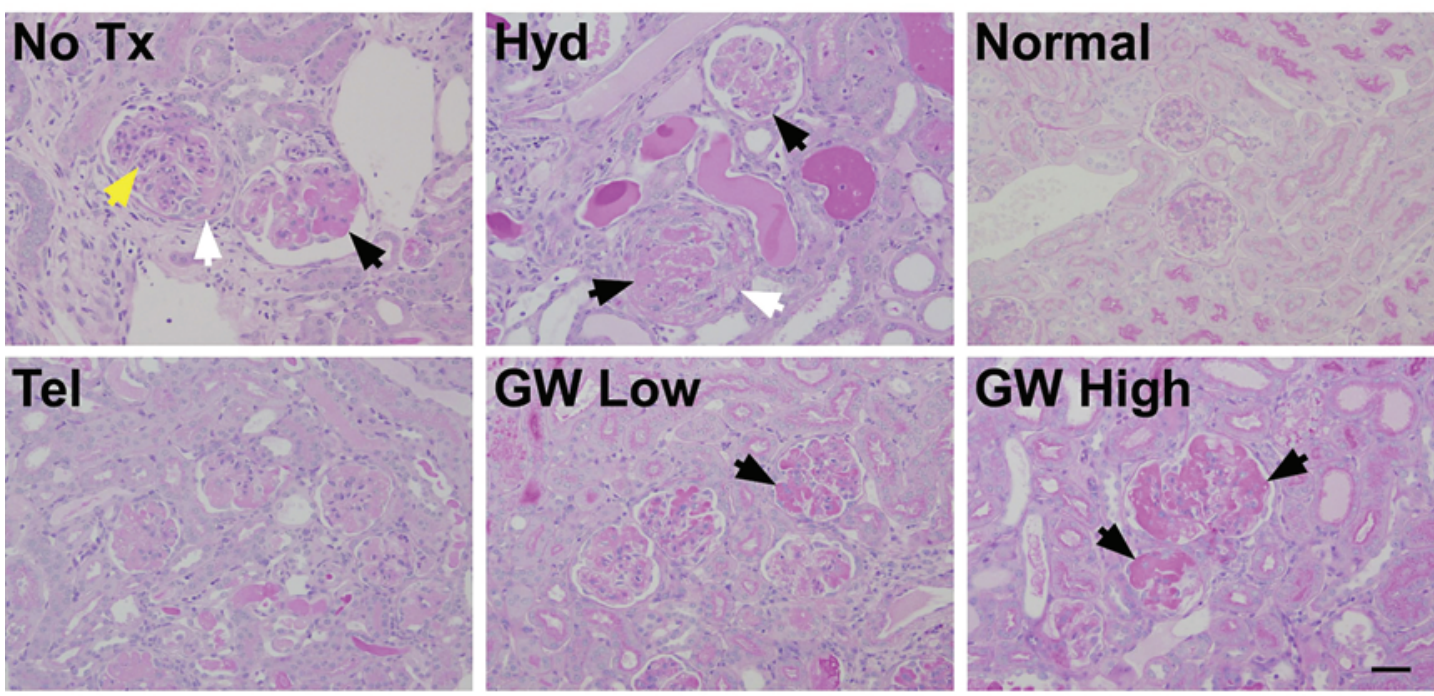

$(100 \mu \mathrm{m})$
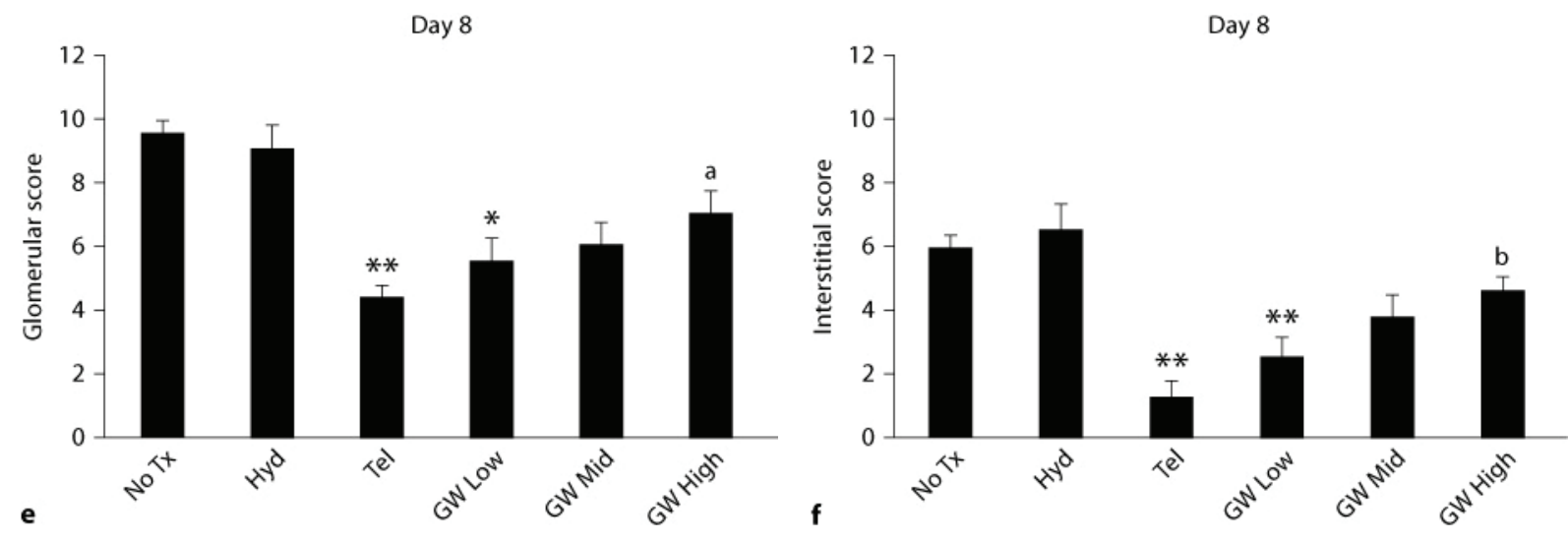

Fig. 4. Kidney sections (PAS; d) and total glomerular (e) and tubulointerstitial (f) scores were estimated in normal mice $(\mathrm{n}=5)$, normal mice injected $10 \mathrm{mg} / \mathrm{kg} /$ day GW9662 (GW Only, $\mathrm{n}=5$ ), nephritic mice without treatment (No Tx, $\mathrm{n}=10)$ and those treated with hydralazine (Hyd, $\mathrm{n}=10)$, telmisartan $($ Tel, $\mathrm{n}=$ 10), telmisartan $+1 \mathrm{mg} / \mathrm{kg} /$ day GW9662 (GW Low, $\mathrm{n}=5$ ), telmisartan $+3 \mathrm{mg} / \mathrm{kg} /$ day GW9662 (GW Mid, $\mathrm{n}=5$ ) or telmisartan $+10 \mathrm{mg} / \mathrm{kg} /$ day GW9662 (GW High, $\mathrm{n}=6$ ). Co-administration of GW9662 abrogated the improved histopathological findings observed in telmisartan-treated mice in a dose-dependent manner. The yellow, black and white arrowheads indicate glomerular proliferation, thrombosis and crescent formation, respectively. ${ }^{*} \mathrm{p}<0.05,{ }^{* *} \mathrm{p}<0.01$, vs. hydralazine, ${ }^{\mathrm{a}} \mathrm{p}<0.05,{ }^{\mathrm{b}} \mathrm{p}<0.01$, vs. telmisartan. 


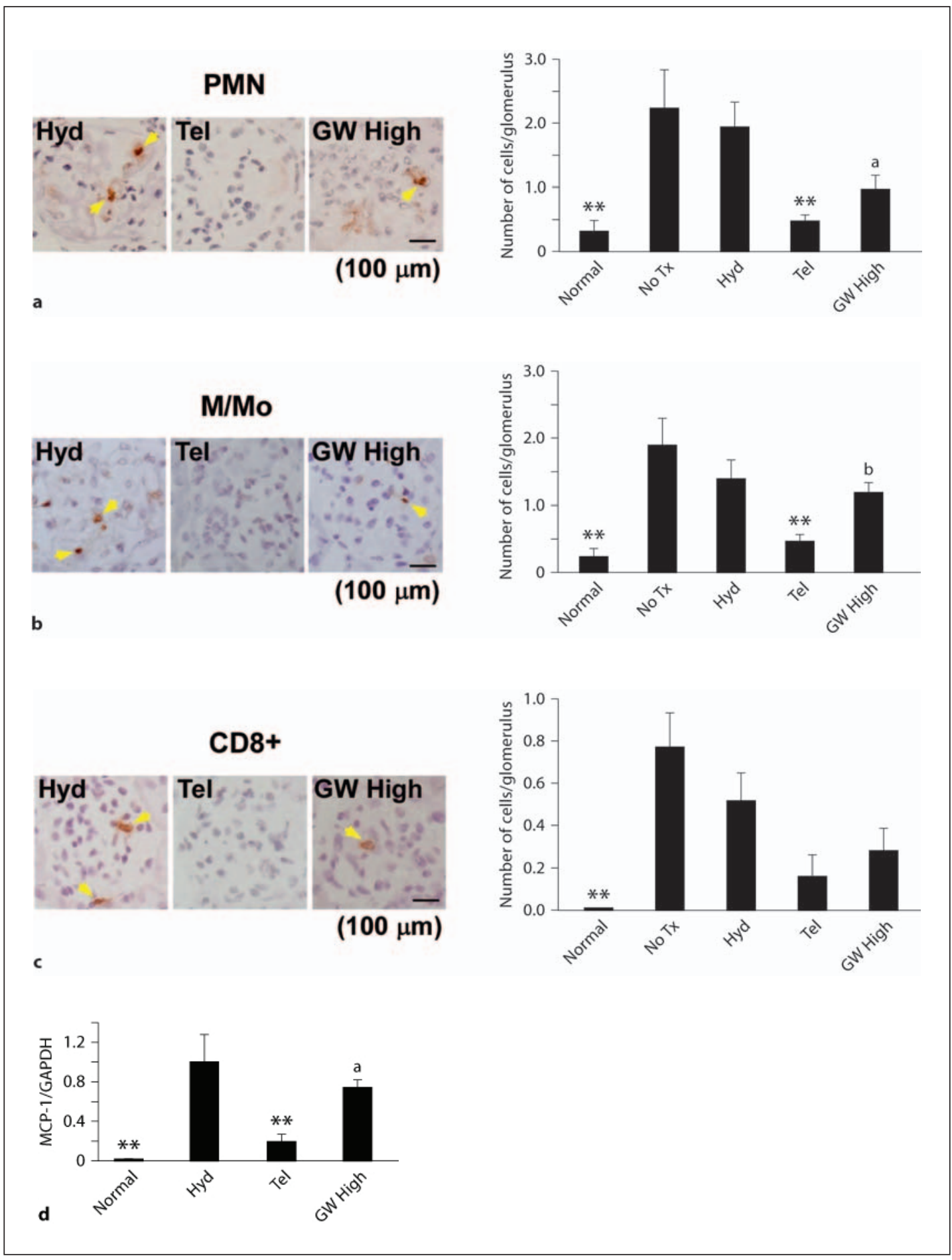

Fig. 5. Kidney sections from hydralazine (Hyd)-, telmisartan (Tel)- or telmisartan $+10 \mathrm{mg} / \mathrm{kg} / \mathrm{day}$ GW9662 (GW High)-treated nephritic mice were stained with antibodies against polymorphonuclear leukocytes (PMN; a), macrophages/monocytes (M/Mo; b) and CD8+ cells (c). Sections were counterstained with Mayer's hematoxylin. d MCP-1 mRNA expression in the cortex of telmisartan- compared with hydralazine-treated mice was significantly decreased and was increased again by the addition of GW9662. ${ }^{* *} \mathrm{p}<0.01$, vs. hydralazine. ${ }^{\mathrm{a}} \mathrm{p}<0.05,{ }^{\mathrm{b}} \mathrm{p}<0.01$, vs. telmisartan. 


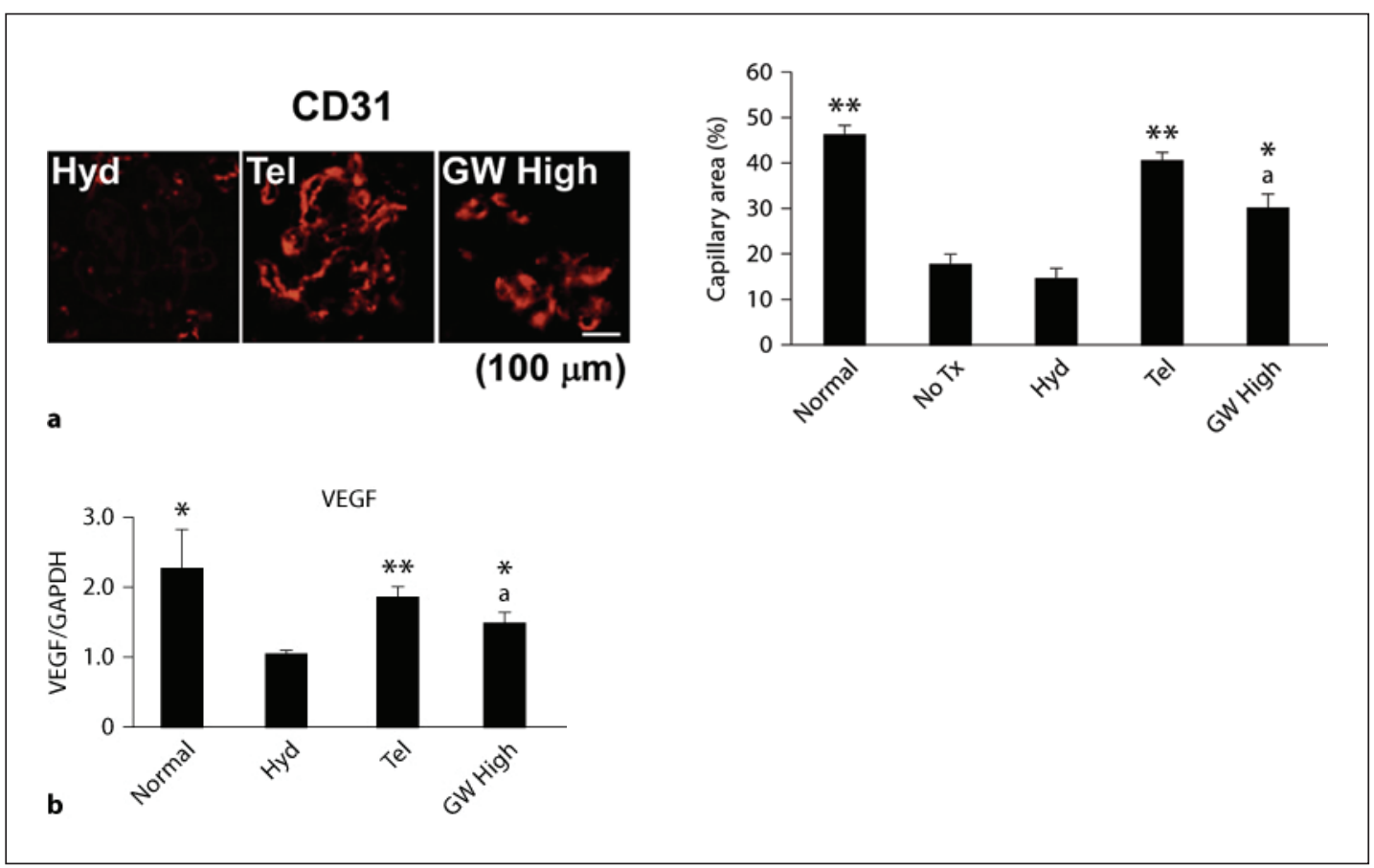

Fig. 6. a Mice without treatment (No Tx) or hydralazine-treated (Hyd) nephritic mice showed reduction of glomerular capillaries compared with normal mice. This was significantly abrogated by telmisartan, and to a lesser extent by co-administration of $10 \mathrm{mg} / \mathrm{kg} /$ day GW9662 (GW High). Representative staining is shown. b VEGF mRNA expression in the cortex was consistent with the density of glomerular capillaries. ${ }^{*} \mathrm{p}<0.05,{ }^{* *} \mathrm{p}<0.01$, vs. hydralazine, ${ }^{\mathrm{a}} \mathrm{p}<0.05$, vs. telmisartan.

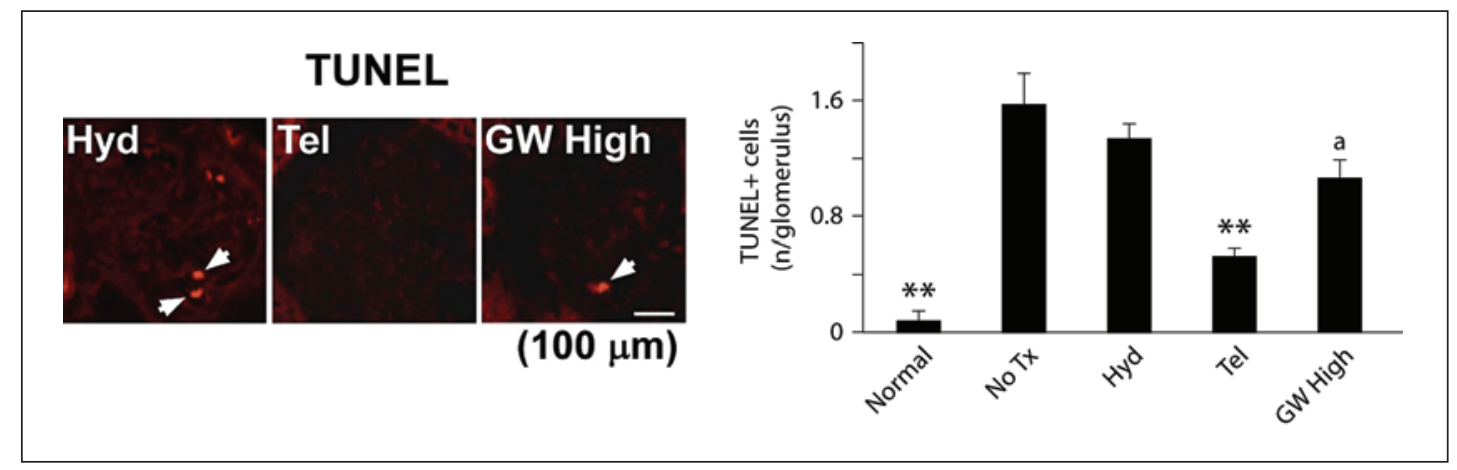

Fig. 7. Telmisartan (Tel) reduced the number of TUNEL-positive cells in the glomeruli, which was prevented by co-administration of $10 \mathrm{mg} / \mathrm{kg} /$ day GW9662 (GW High). Representative staining is shown. ** $\mathrm{p}<0.01$, vs. hydralazine. ${ }^{\mathrm{a}} \mathrm{p}<0.05$, vs. telmisartan.

along with the density of glomerular capillaries was reversed by telmisartan, and to a lesser extent by GW High (fig. 6). The number of glomerular apoptotic cells was increased over normal levels on day 8 . This increase was significantly inhibited by telmisartan (fig. 7). In summarizing these observations, glomerular inflammation, endothelial damage and apoptosis were dramatically suppressed by temporary administration of telmisartan at the initial stage of anti-GBM disease, which was also reversed by co-administration of GW9662 (fig. 5-7). 


\section{Discussion}

Angiotensin II blockade applied at the initial stage of anti-GBM disease in mice significantly inhibited its progression as determined on days 8 and 13. Since the levels of antibodies in the GBM, complement and blood pressure were similar among telmisartan-, losartan- and hydralazine-treated mice, marked amelioration of renal injuries in ARB-treated mice is not believed to be due to differences in antibody production, complement activation and blood pressure. The deposition of anti-GBM antibodies in the GBM initiates the release of renin and angiotensinogen, and robust RAS activation occurs within $24 \mathrm{~h}$ after the induction of anti-GBM disease $[5,14]$. Angiotensin II is also a potent inducer of MCP-1 and pro-inflammatory cytokines, and numerous studies suggest that MCP-1 plays an important role in the progression of anti-GBM disease with irreversible damage $[5,15]$. In previous studies, blockade of the angiotensin II cascade on inflammatory and/or resident cells inhibited glomerular inflammation by decreasing pro-inflammatory mediators such as MCP-1, TNF- $\alpha$, IL- 6 and regulating the differentiation and activation of M1 and M2 macrophages [15, 16]. This may be relevant to the observations in our present study in which the temporary blockade of $\mathrm{AT}_{1} \mathrm{R}$ at an early stage dramatically suppressed glomerular inflammation.

This study showed that telmisartan was significantly more effective than losartan in blocking the progression of anti-GBM disease. Moreover, this dramatic effect of telmisartan was due to its temporary blockade of angiotensin II when used at the initial stage of antiGBM disease. A possible explanation is that the half-life of telmisartan is approximately $24 \mathrm{~h}$ while that of losartan and the active metabolite, EXP3174, is 2.1 and $6.3 \mathrm{~h}$, respectively [17]. However, the ARBs exhibited the same degree of blood pressure lowering on days 4 and 8. Alternatively, there may be a difference in lipophilicity between telmisartan and losartan [18]. Telmisartan is the ARB with the highest lipophilicity and penetrates easily into the tissues or cells in contrast to EXP3174 with the lowest lipophilicity. Takai et al. [18] suggested that the lipophilicity of telmisartan reduces oxidative stress in vascular tissues and protects vascular function in stroke-prone spontaneously hypertensive rats. Thus, telmisartan may preserve the glomerular and interstitial capillaries and suppress the progression of glomerular sclerosis more efficiently than losartan during anti-GBM nephritis.

It is known that telmisartan exhibits the highest PPAR- $\gamma$ agonistic activity among ARBs [11]. Our results using GW9662 clearly showed that PPAR- $\gamma$ activity in telmisartan inhibited the progression of anti-GBM disease in mice. Interestingly, the renal injuries of telmisartantreated mice given PPAR- $\gamma$ inhibitor were almost similar to those of losartan-treated mice. This suggests that the difference between telmisartan and losartan applied during anti-GBM disease may be associated with PPAR- $\gamma$ agonistic activity.

Furthermore, glomerular inflammation and capillary reduction were significantly inhibited by the agonistic property of PPAR- $\gamma$. PPAR- $\gamma$ agonists exert anti-inflammatory effects in numerous disease models, including atherosclerosis and inflammatory bowel disease [19], and also exert anti-inflammatory effects in human subjects with type 2 diabetes [10]. PPAR $\gamma$ is expressed in macrophages and inhibits a subset of inflammatory responsive genes in macrophages, including MCP-1, TNF- $\alpha$ and IL-1 $\beta$ [19]. The deletion of PPAR- $\gamma$ from macrophages results in more severe diet-induced insulin resistance, suggesting that the adipose tissue macrophages are major sources of pro-inflammatory mediators that induce an insulin-resistant state and PPAR- $\gamma$ functions in part as a negative regulator of macrophage activation [20].

This study showed that PPAR- $\gamma$ agonistic action significantly induced neoangiogenesis and elevated VEGF expression during anti-GBM disease. Although angiogenic potentials of PPAR- $\gamma$ agonists have been intensively investigated, it remains to be established whether they are angiogenic or anti-angiogenic. Nonetheless, the selective PPAR- $\gamma$ activation resulted in 
neoangiogenesis of mouse cornea through the upregulation of VEGF [21]. Moreover, tumor growth was enhanced in mice implanted with tumor cells with constitutively active PPAR- $\gamma$, which was associated with increased angiogenic factors such as angiopoietin-like 4, VEGF and fibroblast growth factors 1 and 9 [22]. Rosiglitazone ameliorated endothelial dysfunction in type 2 diabetes patients and increased the number and migratory activity of endothelial progenitor cells $[21,23]$. This may be related to the upregulation of VEGF since it increases vascular permeability and contributes to the development of edema, which is also a common side effect of thiazolidinediones [24].

In conclusion, we demonstrated that the temporary administration of telmisartan at the initial stage of anti-GBM disease significantly inhibited its progression. Losartan showed a similar effect but was less effective. Telmisartan provided additional therapeutic benefits by suppressing glomerular inflammation and endothelial injury through its PPAR- $\gamma$-mediated effects. These findings present new information to understand the biological and therapeutic effects of telmisartan with a potentially important implication for the management of patients with immune-mediated renal damage.

\section{Acknowledgments}

We are grateful to Ms. Ikumi Satoh and Mr. Ryota Shirai for technical assistance.

\section{Disclosure Statement}

The authors declare no conflicts of interest.

\section{References}

1 Park SY, Ueda S, Ohno H, Hamano Y, Tanaka M, Shiratori T, Yamazaki T, Arase H, Arase N, Karasawa A, Sato S, Ledermann B, Kondo Y, Okumura K, Ra C, Saito T: Resistance of Fc receptor-deficient mice to fatal glomerulonephritis. J Clin Invest 1998;102:1229-1238.

2 Shimizu A, Kitamura H, Masuda Y, Ishizaki M, Sugisaki Y, Yamanaka N: Rare glomerular capillary regeneration and subsequent capillary regression with endothelial cell apoptosis in progressive glomerulonephritis. Am J Pathol 1997;151:1231-1239.

3 Isome M, Fujinaka H, Adhikary LP, Kovalenko P, El-Shemi AG, Yoshida Y, Yaoita E, Takeishi T, Takeya M, Naito M, Suzuki H, Yamamoto T: Important role for macrophages in induction of crescentic anti-GBM glomerulonephritis in WKY rats. Nephrol Dial Transplant 2004;19:2997-3004.

4 Shimizu A, Masuda Y, Mori T, Kitamura H, Ishizaki M, Sugisaki Y, Fukuda Y: Vascular endothelial growth factor 165 resolves glomerular inflammation and accelerates glomerular capillary repair in rat anti-glomerular basement membrane glomerulonephritis. J Am Soc Nephrol 2004;15:2655-2665.

5 Hisada Y, Sugaya T, Yamanouchi M, Uchida H, Fujimura H, Sakurai H, Fukamizu A, Murakami K: Angiotensin II plays a pathogenic role in immune-mediated renal injury in mice. J Clin Invest 1999; 103:627-635.

6 Barnett AH, Bain SC, Bouter P, Karlberg B, Madsbad S, Jervell J, Mustonen J: Angiotensin-receptor blockade versus converting-enzyme inhibition in type 2 diabetes and nephropathy. $\mathrm{N}$ Engl J Med 2004;351:1952-1961.

7 Li PK, Leung CB, Chow KM, Cheng YL, Fung SK, Mak SK, Tang AW, Wong TY, Yung CY, Yung JC, Yu AW, Szeto CC: Hong Kong study using valsartan in IgA nephropathy (HKVIN): a double-blind, randomized, placebo-controlled study. Am J Kidney Dis 2006;47:751-760.

8 Lehmann JM, Moore LB, Smith-Oliver TA, Wilkison WO, Willson TM, Kliewer SA: An antidiabetic thiazolidinedione is a high affinity ligand for peroxisome proliferator-activated receptor $\gamma$ (PPAR $\gamma$ ). J Biol Chem 1995;270:12953-12956. 


\begin{tabular}{l}
\begin{tabular}{l}
\hline Nephron Extra 2011;1:78-90 \\
\hline DOI: 10.1159/000331704
\end{tabular} \\
$\begin{array}{l}\text { Published online: September 22, } 2011 \\
\text { www.karger.com/nne }\end{array}$ \\
\hline
\end{tabular}

Hamano et al.: PPAR- $\gamma$ and Anti-GBM Disease

9 Chawla A: Control of macrophage activation and function by PPARs. Circ Res 2010;106:1559-1569.

10 Ceriello A: Thiazolidinediones as anti-inflammatory and anti-atherogenic agents. Diabetes Metab Res Rev 2008;24:14-26.

11 Benson SC, Pershadsingh HA, Ho CI, Chittiboyina A, Desai P, Pravenec M, Qi N, Wang J, Avery MA, Kurtz TW: Identification of telmisartan as a unique angiotensin II receptor antagonist with selective PPAR $\gamma$-modulating activity. Hypertension 2004;43:993-1002.

12 Hamano Y, Okude T, Shirai R, Sato I, Kimura R, Ogawa M, Ueda Y, Yokosuka O, Kalluri R, Ueda S: Lack of collagen XVIII/endostatin exacerbates immune-mediated glomerulonephritis. J Am Soc Nephrol 2010;21:1445-1455.

13 Hamano Y, Aoki T, Shirai R, Hatano M, Kimura R, Ogawa M, Yokosuka O, Ueda S: Low-dose darbepoetin $\alpha$ attenuates progression of a mouse model of aristolochic acid nephropathy through early tubular protection. Nephron Exp Nephrol 2010;114:e69-e81.

14 Boyce NW, Holdsworth SR: Intrarenal hemodynamic alterations induced by anti-GBM antibody. Kidney Int 1987;31:8-14.

15 Ruiz-Ortega M, Bustos C, Hernandez-Presa MA, Lorenzo O, Plaza JJ, Egido J: Angiotensin II participates in mononuclear cell recruitment in experimental immune complex nephritis through nuclear factor- $\kappa \mathrm{B}$ activation and monocyte chemoattractant protein-1 synthesis. J Immunol 1998;161: 430-439.

16 Aki K, Shimizu A, Masuda Y, Kuwahara N, Arai T, Ishikawa A, Fujita E, Mii A, Natori Y, Fukunaga Y, Fukuda Y: Ang II receptor blockade enhances anti-inflammatory macrophages in anti-glomerular basement membrane glomerulonephritis. Am J Physiol Renal Physiol 2010;298:F870-F882.

17 Wienen W, Entzeroth M, Van Meel JC, Stangier J, Busch U, Ebner T, Schmid J, Lehmann H, Matzek K, Kempthorne-Rawson J, Gladigau V, Hauel N: A review on telmisartan: a novel, long-acting angiotensin II-receptor antagonist. Cardiovasc Drug Rev 2000;18:127-156.

18 Takai S, Kirimura K, Jin D, Muramatsu M, Yoshikawa K, Mino Y, Miyazaki M: Significance of angiotensin II receptor blocker lipophilicities and their protective effect against vascular remodeling. Hypertens Res 2005;28:593-600.

19 Saijo K, Crotti A, Glass CK: Nuclear receptors, inflammation, and neurodegenerative diseases. Adv Immunol 2010;106:21-59.

20 Hevener AL, Olefsky JM, Reichart D, Nguyen MT, Bandyopadyhay G, Leung HY, Watt MJ, Benner C, Febbraio MA, Nguyen AK, Folian B, Subramaniam S, Gonzalez FJ, Glass CK, Ricote M: Macrophage PPAR $\gamma$ is required for normal skeletal muscle and hepatic insulin sensitivity and full antidiabetic effects of thiazolidinediones. J Clin Invest 2007;117:1658-1669.

21 Biscetti F, Gaetani E, Flex A, Aprahamian T, Hopkins T, Straface G, Pecorini G, Stigliano E, Smith RC, Angelini F, Castellot JJ Jr, Pola R: Selective activation of peroxisome proliferator-activated receptor (PPAR) $\alpha$ and PPAR $\gamma$ induces neoangiogenesis through a vascular endothelial growth factordependent mechanism. Diabetes 2008;57:1394-1404.

22 Tian L, Zhou J, Casimiro MC, Liang B, Ojeifo JO, Wang M, Hyslop T, Wang C, Pestell RG: Activating peroxisome proliferator-activated receptor $\gamma$ mutant promotes tumor growth in vivo by enhancing angiogenesis. Cancer Res 2009;69:9236-9244.

23 Pistrosch F, Passauer J, Fischer S, Fuecker K, Hanefeld M, Gross P: In type 2 diabetes, rosiglitazone therapy for insulin resistance ameliorates endothelial dysfunction independent of glucose control. Diabetes Care 2004;27:484-490.

24 Dvorak HF, Brown LF, Detmar M, Dvorak AM: Vascular permeability factor/vascular endothelial growth factor, microvascular hyperpermeability, and angiogenesis. Am J Pathol 1995;146:1029-1039. 